\title{
Meningococcal disease serogroup C
}

\author{
This article was published in the following Dove Press journal: \\ Risk Management and Healthcare Policy \\ 6 March 2012 \\ Number of times this article has been viewed
}

\section{Félix O Dickinson' \\ Antonio E Pérez' \\ Iván E Cuevas² \\ 'Department of Epidemiology, "Pedro Kourí" Institute, Havana, Cuba; ${ }^{2}$ Pharmacovigilance Group, Finlay Institute, Havana, Cuba}

Correspondence: Félix Dickinson

"Pedro Kouri" Institute, PO Box 60I,

Marianao 13, Havana, Cuba

$\mathrm{Tel}+537205321 \mathrm{I}$

Fax +537 204605 I

Email dickinson@ipk.sld.cu; fodickinson@infomed.sld.cu
Abstract: Despite current advances in antibiotic therapy and vaccines, meningococcal disease serogroup C (MDC) remains a serious threat to global health, particularly in countries in North and Latin America, Europe, and Asia. MDC is a leading cause of morbidity, mortality, and neurological sequelae and it is a heavy economic burden. At the individual level, despite advances in antibiotics and supportive therapies, case fatality rate remains nearly $10 \%$ and severe neurological sequelae are frequent. At the population level, prevention and control of infection is more challenging. The main approaches include health education, providing information to the public, specific treatment, chemoprophylaxis, and the use of vaccines. Plain and conjugate meningococcal $\mathrm{C}$ polysaccharide vaccines are considered safe, are well tolerated, and have been used successfully for over 30 years. Most high-income countries use vaccination as a part of public health strategies, and different meningococcal $\mathrm{C}$ vaccination schedules have proven to be effective in reducing incidence. This is particularly so with conjugate vaccines, which have been found to induce immunogenicity in infants (the age group with the highest incidence rates of disease), stimulate immunologic memory, have longer effects, not lead to hyporesponsiveness with repeated dosing, and decrease acquisition of nasopharyngeal carriage, inducing herd immunity. Antibiotics are considered a cornerstone of MDC treatment and must be administered empirically as soon as possible. The choice of which antibiotic to use should be made based on local antibiotic resistance, availability, and circulating strains. Excellent options for a 7-day course are penicillin, ampicillin, chloramphenicol, and third-generation cephalosporins (ceftriaxone and cefotaxime) intravenously, although the latter are considerably more expensive than the others. The use of steroids as adjunctive therapy for MDC is still controversial and remains a topic of debate. A combination of all of the aforementioned approaches is useful in the prevention and control of MDC, and each country should tailor its public health policy to its own particular needs and knowledge of disease burden.

Keywords: epidemiology, public health significance, vaccination strategies, disease management

\section{Introduction}

Despite current advances in antibiotic therapy and vaccines, as well as the availability of sophisticated intensive care, Neisseria meningitidis remains a major cause of meningitis and meningococcemia, and, less commonly, a cause of pneumonia, septic arthritis, pericarditis, and conjunctivitis, in hundreds of thousands of individuals worldwide each year. ${ }^{1-5}$ There are several issues that underline its importance. Meningococcal disease (MD) can be rapidly progressive and fatal in previously healthy individuals. ${ }^{6}$ Also, it is a leading cause of morbidity and mortality in all age groups worldwide, submit your manuscript | www.dovepress.com

Dovepress

http://dx.doi.org/10.2147/RMHP.SI2711
Risk Management and Healthcare Policy 20I2:5 I-I5

(C) 2012 Dickinson et al, publisher and licensee Dove Medical Press Ltd. This is an Open Access article which permits unrestricted noncommercial use, provided the original work is properly cited. 
although young children and adolescents are at particular risk. ${ }^{7,8}$ Most cases are sporadic, but case cluster, outbreaks, epidemics, and pandemics have been reported in different regions of the world. ${ }^{5}$ It is common for survivors of MD to develop permanent sequelae, such as skin scarring, abnormal bone growth, limb loss and multiple amputations, hearing loss, cognitive deficits, visual impairment, educational difficulties, developmental delays, motor nerve deficits, seizure disorders, and behavioral problems. ${ }^{8-11}$

Six major disease-causing $N$. meningitidis serogroups (A, B, C, W-135, X, and $\mathrm{Y}$ ) are responsible for nearly $90 \%$ of disease worldwide. ${ }^{1,7,12,13}$ MD serogroup C (MDC) remains a serious threat to global health, ranking as the second most common serogroup causing disease in North and Latin America, Europe, and Asia, ${ }^{14-17}$ exceeded only by MD serogroups A and $\mathrm{B}$. The purpose of this review is to discuss the current epidemiology, management, and public health implications of MDC. Experiences with available meningococcal $\mathrm{C}$ vaccines will also be reviewed, and their potential public health impact will be considered.

\section{Epidemiology}

A remarkable characteristic of MD is its complex, fluid, and changing epidemiology. It has major cyclical incidence fluctuations in endemic disease and epidemics, as well as a highly regional serogroup distribution. ${ }^{1,12,18}$ Because of this, reliable surveillance systems are essential for adequate monitoring of local epidemiology and disease burden, as well as monitoring of the impact of control and prevention measures. The reporting of clinically diagnosed MD to local public health authorities is legally mandatory in most parts of the world. ${ }^{1,19,20}$ Among the variety of methods for conducting meningococcal surveillance, ${ }^{21}$ the gold standard is laboratory-based surveillance, mostly used in countries with high economic resource, where high-standard laboratories are able to identify bacteria in cerebrospinal fluid (CSF), blood, or other normally sterile body fluids by culture or polymerase chain reaction (PCR). ${ }^{1}$ In some countries, non-culture-based approaches such as latex agglutination and counterimmunoelectrophoresis are frequently used to supplement cultures. ${ }^{22}$ Since the mid-1990s, PCR-based approaches have increasingly been used to identify patients with meningococcal infection. ${ }^{23}$ In resource-poor countries, where laboratory facilities are scarce or inaccessible, surveillance is based on a simple case definition, and only a modest proportion of cases may be confirmed using laboratory methods. ${ }^{24,25}$

$N$. meningitidis is a Gram-negative diplococcus classified into 13 serogroups based on the immunogenicity and structure of the polysaccharide capsule. Further classification into serosubtype, serotype, and immunotype is based on class 1 outer membrane proteins, class 2 or 3 outer membrane proteins, and lipopoly(oligo)saccharide structure, respectively. ${ }^{5,8}$

Humans are the only natural host for meningococcus, a frequent member of human pharynx and upper respiratory flora. ${ }^{26,27}$ Somewhere between $8 \%$ and $25 \%$ of the general population may be asymptomatic carriers, translating to hundreds of millions of carriers worldwide. Adolescents are considered a major reservoir. The principal route of meningococcal transmission is person-to-person contact via respiratory droplets or oral secretions from an asymptomatic carrier or individual with invasive disease. A contaminated vehicle (eg, a cigarette, food utensils, or drink bottle) may also spread bacteria, but the risk of such transmission is very low. The disease incubation period can vary from 1 to 10 days, but the average is $2-4$ days., ${ }^{5,26}$ The patient remains infectious for as long as meningococci are present in respiratory/oral secretions, or for 24 hours after initiation of effective antibiotic treatment.

In a minority of exposed individuals $(<1 \%), N$. meningitidis penetrates the nasopharyngeal mucosa, reaches the bloodstream, and progresses to invasive disease..$^{5,8,26}$ The ability to cause invasive disease depends on environmental factors, meningococcal virulence factors, and lack of a host protective immune response. The most common known risk factors for MD include active and passive smoking, ${ }^{8}$ travel to epidemic areas, ${ }^{27}$ crowding, exposure to low humidity, dust and coinfections, deficiencies in terminal complement components, asplenia, and deficiencies in mannose-binding lectin. ${ }^{28-30}$ Other main factors depend on the agent, such as hypervirulent lineages (eg, serogroup C ST-11 complex/ET-37 complex and ST-8 complex/cluster A4). ${ }^{1}$

Although MD occurs throughout the year, incidence peaks in late winter and early spring. ${ }^{26} \mathrm{MD}$ affects persons of all ages, but the highest rates are seen in infants and children under 4 years old and in adolescents. ${ }^{5}$ In the United States and Canada, the incidence has fluctuated between approximately 0.5 and 1.5 cases per 100,000 population per year. ${ }^{2,31}$ In both countries, serogroup $\mathrm{C}$ ranks the second most common serogroup causing disease after serogroups $\mathrm{Y}$ and $\mathrm{B}$, respectively. ${ }^{1}$ Reporting from Latin America and the Caribbean has been characterized by marked differences from country to country. The overall incidence of MD varied per year from under 0.1 to 2.0 cases per 100,000 population. Serogroups B and $\mathrm{C}$ are responsible for the majority of reported cases, but the emergence of serogroups $\mathrm{W}-135$ and $\mathrm{Y}$ has been reported in 
some countries..$^{32,33}$ The African "meningitis belt" experiences periodic and large epidemics of serogroup A MD, showing the highest incidence of any region in the world. ${ }^{1}$ The epidemiology of MD is well characterized in most European countries, although less information is available from in the eastern. The vast majority of cases are caused by serogroup $B$ and $C$ strains, and overall incidence of laboratory-confirmed disease is nearly 1.0 case per 100,000 population..$^{34}$ The epidemiology of MD in much of Asia is likely to be highly heterogeneous and incompletely understood, in part because of the absence of surveillance in many countries, poor bacterial detection methods, and social and health care barriers to disease reporting. ${ }^{19}$ With the exceptions of Mongolia (13.0 cases per 100,000 population $)^{35}$ and China (2.1 cases per 100,000 population), ${ }^{36}$ most Asian countries have reported rates lower than 1.0 cases per 100,000 population. ${ }^{19}$ Serogroup $C$ is playing an increasing role in Asia; since 2002, serogroup C has become established in some provinces of China, where it has been responsible for local outbreaks. ${ }^{1,19,36}$ Serogroup C also plays a significant role in disease in Singapore. ${ }^{19}$ In Australasia, the epidemiology of MD follows the pattern seen in other industrialized nations. In the mid-1990s, Australia observed increases in incidence rates of MDC; in New Zealand, the incidence increased markedly because of the emergence and spread of a ST-41/44 clonal complex/lineage 3 serogroup B clone. ${ }^{1}$

The case fatality rate in North America, Europe, and other high-income countries is nearly $8 \%$, but the rate can be higher than $20 \%$ in resource-poor countries. ${ }^{1}$ The largest MDC epidemics reported by the World Health Organization ${ }^{23}$ between 1970 and 1996 occurred in Brazil (São Paulo, 1971-1972), Vietnam (Ho Chi Minh City, 1977), and Burkina Faso (Diapaga, 1979). Case clusters and outbreaks were seen in Canada and the US (1992-1993) and in Spain $(1995-1997) .^{37-39}$

\section{Public health}

From the perspective of public health, dealing with MD is a very challenging situation. This much-feared disease is frequently a source of community and political concern, often receiving a high level of media attention. In many regions of the world, MDC is responsible for unexpected outbreaks and large epidemics, also causing high mortality as well as permanent and severe physical and neurological sequelae in survivors, with a substantial burden of disease. ${ }^{40}$

The main lines of public health against MDC are prevention (before a case occurs) and control (after a case is diagnosed). In most countries the government is responsible for public health measures, including health promotion, and health service administration; in some countries the private sector and nongovernmental organizations also contribute.

One of the most important preventive actions toward MDC is to raise awareness among the population and health professionals. Information about the disease should be available for the community, particularly information regarding the main signs and symptoms and the importance of seeking early medical attention. ${ }^{41}$ Public health system policies should ensure that cases are referred early to hospital, receiving opportune and adequate medical attention. Also, policies must ensure there are efficient surveillance and response systems in place, allowing a prompt and timely diagnosis and reporting, endorsing control activities for close contacts of the cases.

In prevention of $\mathrm{MDC}$, the striking regional variability in disease emphasizes the need for country-specific approaches to vaccine prevention. ${ }^{39}$ As well as this regional variability, the burden of MDC still remains unknown for many parts of the world because of inadequate surveillance, severely hampering the implementation of appropriate prevention strategies. Suitable surveillance of populations - especially those at high risk such as infants and teenagers, ${ }^{39,41,42}$ unprivileged populations and ethnic minorities, and travelers ${ }^{43}-$ is essential for implementation of an appropriate prevention policy.

Over the past decade, substantial advances in meningococcal vaccine development have occurred, and much has been learned about prevention from countries that have incorporated those vaccines into their immunization programs. For countries with meningococcal vaccination policies, research on vaccine effectiveness and impact, including indirect effects, is crucial for informing policy decisions. Each country should tailor meningococcal vaccination policy according to their particular needs and knowledge of disease burden.

The introduction of new vaccines is an increasingly complex and political process inevitably prone to controversy. Cost-effectiveness economic analysis of vaccination strategies is essential and provides a framework for evaluation of such strategies, supporting their benefit. ${ }^{44}$ Commercial development of new vaccines by pharmaceutical companies tends to develop those products for which there is a big demand in the industrialized world. ${ }^{45}$

Most developed countries have introduced meningococcal $\mathrm{C}$ vaccination into their national immunization programs, because vaccination has been demonstrated to be the most successful prevention strategy for confronting MDC. Bivalent (A, C, and BC), trivalent (A, C, W-135), 
and quadrivalent (A, C, Y, W-135) polysaccharide vaccines have already been licensed and made available ${ }^{13,46}$ for some time, but recent serogroup $\mathrm{C}$ conjugate vaccines confer immunologic advantages over polysaccharide vaccines, including the ability to induce a herd immunity effect and to stimulate immunologic memory. ${ }^{46}$ The use of these vaccines by public health decision makers has been recommended by the World Health Organization. ${ }^{45,47}$

Different meningococcal $\mathrm{C}$ vaccination schedules have proven to be effective in reducing incidence. ${ }^{48}$ In the United Kingdom (UK), all childhood immunizations and nationally recommended immunizations for adults are provided free. ${ }^{45}$ Other countries, industrialized and nonindustrialized, also provide free vaccination to the general population. ${ }^{45,49}$ In 1999, the UK was the pioneer in including serogroup C conjugate vaccines in childhood vaccination schedules. ${ }^{50}$ Other industrialized countries in Europe, North America, and other regions where MDC is prevalent ${ }^{44,45,51-53}$ have also included serogroup $\mathrm{C}$ conjugate vaccines in public health policy, decreasing incidence rates of the disease significantly. Among Latin American countries, Brazil is the only country that has begun to introduce the serogroup $\mathrm{C}$ conjugate vaccine into the routine immunization schedule. ${ }^{46,32}$ During an MD epidemic, due to serogroups $\mathrm{C}$ and $\mathrm{B}, \mathrm{Cuba}$, implemented a high-coverage mass vaccination campaign in 1979, using a commercially available polysaccharide AC vaccine, achieving a substantial decrease in the incidence due to serogroup C. In the late 1980s a high-coverage mass vaccination was arranged in Cuba with meningococcal $\mathrm{BC}$ vaccine (VA-MENGOC-BC ${ }^{\circledR}$ ) obtained by the Finlay Institute in Havana, Cuba. This vaccine is the first of its type in the world - that is, safe, effective, and commercially available for preventing MD caused by serogroup B, while also efficiently preventing serogroup C. ${ }^{53}$ Since 1991 , this vaccine has been successfully used in the Cuban routine childhood two-dose vaccination schedule. ${ }^{54}$ The incidence of disease caused by the epidemic strain (B:4:P1.19,15) has been reduced significantly, and there is a total absence of autochthonous cases due to serogroup $\mathrm{C}$, demonstrating the impact of this intervention. ${ }^{49,53,54}$ Subsequent molecular studies ${ }^{55}$ have shown the significant reduction of the frequency and diversity of hypervirulent clonal complexes, also affecting the genetic composition of the carrier-associated meningococcal isolates after vaccination.

In East Asia and the southern Pacific, polysaccharide and conjugate serogroup $\mathrm{C}$ vaccines are available but are not often used as a part of routine immunization schedules. ${ }^{46}$ In China, polysaccharide $\mathrm{AC}$ vaccine has been used to prevent MDC epidemics. ${ }^{56} \mathrm{New}$ Zealand does not include serogroup $\mathrm{C}$ vaccine on their immunization program at the present time, considering the very low incidence of disease ( 0.48 cases per 100,000 population) ${ }^{57}$

Nonvaccination of population may lead to pockets of susceptible individuals in a population, increasing the risk of disease, and, at some point, sporadic cases, and the risk of potential outbreaks or epidemics. Therefore, an efficient surveillance system is required to detect any changes of disease incidence in a timely manner and to put into action the most appropriate prevention and control strategy.

On the other hand, one of the most important public health actions after identifying a case of MD is to prevent secondary cases among the patient's close contacts, through chemoprophylaxis and efficient surveillance. ${ }^{58-61}$ The definition of intimate contact is not very accurate and it can include a large number of people. ${ }^{62}$ This concept should refer to all people who have had prolonged ( 8 hours or more) and close (within 3 feet) contact with the patient or who have been directly exposed to oral secretions (face-to-face contact, mouth-to-mouth resuscitation, kissing, or management of an endotracheal tube) of the patient within 1 week before the onset of symptoms until 24 hours after appropriate antimicrobial therapy has been initiated. Such persons typically include members of the patient's household or the patient's roommates, persons at a child-care center, and others who have had prolonged exposure to the infected patient. ${ }^{58}$

Although the risk to contacts may be low, the highest absolute and relative risk is to people who live in the same household as the MD patient, ${ }^{41}$ particularly those who share bedrooms. ${ }^{58}$ The aim of chemoprophylaxis is to reduce the risk of disease directly by eradicating nasopharyngeal carriage of meningococci from any carrier who may be in the network of contacts close to each index case. ${ }^{40,59,60}$ Therefore, chemoprophylaxis should be offered to close contacts of cases, irrespective of vaccination status. ${ }^{59,60}$

Most approaches to chemoprophylaxis include a short course of antibiotics such as rifampicin $(10 \mathrm{mg} / \mathrm{kg}$ body weight every 12 hours orally in children; $600 \mathrm{mg}$ daily for 2 days in adults) or, as an alternative, ciprofloxacin (500 mg orally once) or ceftriaxone (125 mg once intramuscularly in children; $250 \mathrm{mg}$ once intramuscularly for those aged 15 years or older). ${ }^{58-61}$ Ideally, chemoprophylaxis should be started within 24 hours after the index case has been identified, although diminishing levels of benefit may still be realized even with delays of up to 2 weeks. ${ }^{58,61}$

Despite heavy community pressure to "do something" immediately in response to a death from MD, epidemiological 
criteria should prevail in reaching a decision on whether or not to advise chemoprophylaxis and postexposure vaccination. Immunization must be considered as a component of acute care in the setting of newly diagnosed infection, and serogroup $C$ meningococcal vaccine should be offered to close contacts..$^{57,59,63}$ The rationale for vaccination is to reduce the ongoing risk of invasive disease in close contacts. ${ }^{60}$

The effectiveness, efficiency, and impact of health actions or interventions are essential in evaluation of health policy. The full value of epidemiological research is only realized when it is translated into health policy and the subsequent planning and implementation of effective prevention and control programs.

Previous considerations illustrate different strategies and the complexity involved in the judgment and selection of the most adequate strategy on public health. The health policy should consider current epidemiology of disease, immunogenicity, and antibody protection persistence in high-risk groups after immunization, vaccine effectiveness, cost-effectiveness, and the costs and benefits of different strategies. Results of these strategies should be monitored systematically.

\section{Vaccination strategies Available meningococcal $C$ vaccines}

Primary prevention of MD is essential for several reasons. The clinical presentation may be fulminant, with no opportunity for antibiotics to influence the course of the disease. Incidence rates of antibiotic-resistant strains are now increasing and chemoprophylaxis of contacts during outbreaks is a complex and often unsuccessful public health measure. There are a range of vaccines available to prevent MDC: plain polysaccharide $\mathrm{C}$ vaccines, conjugate polysaccharide $\mathrm{C}$ vaccines, and a plain polysaccharide $\mathrm{C}+$ outer membrane vesicle of serogroup B vaccine.

\section{Polysaccharide serogroup $C$ vaccines}

The first polysaccharide vaccines, developed approximately 30 years ago, contain purified capsular polysaccharides of $N$. meningitidis. The AC bivalent vaccines and the quadrivalent A, C, W-135, and $\mathrm{Y}$ vaccines are shown in Table 1.

After being administered as part of mass vaccination programs to millions of persons, including military personnel, civilians, and travelers to areas of the world with endemic disease ${ }^{64}$ meningococcal polysaccharides vaccines (bivalent $\mathrm{A}$ and $\mathrm{C}$, quadrivalent $\mathrm{A}, \mathrm{C}, \mathrm{Y}$ and $\mathrm{W}-135$ ) are considered safe and well tolerated. Pain and redness at the injection site are the most commonly reported adverse events (up to $40 \%$ ).
Table I Available serogroup $C$ meningococcal vaccines

\begin{tabular}{|c|c|c|}
\hline Vaccine & Serogroups & Available vaccines \\
\hline \multirow[t]{2}{*}{ Polysaccharide ${ }^{2}$} & $\begin{array}{l}\text { A, C, W-I35, } \\
\text { Y (MPSV4) }\end{array}$ & $\begin{array}{l}\text { Menomune }^{\circledR}, \\
\text { ACWY Vax }^{\circledR}, \\
\text { Mencevax }^{\circledR}\end{array}$ \\
\hline & $A, C$ & $\begin{array}{l}\text { Mengivac }^{\circledR}, A C \operatorname{Vax}^{\circledR}, \\
\text { polysaccharide } \\
\text { meningococcal } \\
A \text { and } C \text { vaccine, }{ }^{3} \\
\text { vax-MEN-AC }{ }^{\circledR}\end{array}$ \\
\hline \multirow[t]{3}{*}{ conjugates $^{2}$} & C & $\begin{array}{l}\text { Menjugate }^{\circledR}, \\
\text { Meningitec }^{\circledR}, \\
\text { NeisVac-C }^{\circledR}\end{array}$ \\
\hline & $\begin{array}{l}\text { A, C, W-I35, } \\
\text { Y (MCV4) }\end{array}$ & Menveo $^{\circledR}$, Menactra $^{\circledR}$ \\
\hline & $\mathrm{C}(+\mathrm{Hib})$ & Menitorix ${ }^{\circledast}$ \\
\hline $\begin{array}{l}\text { Polysaccharide } C+\text { outer } \\
\text { membrane vesicle } \\
\text { of serogroup B strain specific }{ }^{53}\end{array}$ & $\mathrm{C}$ and $\mathrm{B}$ & VA-MENGOC-BC ${ }^{\circledR}$ \\
\hline
\end{tabular}

Notes: Menomune and Menactra are registered trademarks of Sanofi Pasteur; ACWY Vax, Mencevax, AC Vax, and Menitorix are registered trademarks of GlaxoSmithKline; Mengivac is a registered trademark of Aventis Pasteur; polysaccharide meningococcal $A$ and $C$ vaccine is produced by Bio-Manguinhos, which fills the vaccine using bulbs manufactured at the Finlay Institute, Havana, Cuba; vax-Men-AC and VA-MENGOC$\mathrm{BC}$ are registered trademarks of the Finlay Institute; Meningitec is a registered trademark of Wyeth; Neis Vac-C is a registered trademark of Baxter Healthcare. ${ }^{63}$

Abbreviations: Hib, Haemophilus influenzae type B; MCV4, quadrivalent meningococcal conjugate; MPSV4, quadrivalent meningococcal polysaccharide.

These local reactions are typically of mild severity and last for 1-2 days. Transient low-grade fevers $\left(>38.4^{\circ} \mathrm{C}\right)$ occur in less than $1 \%$ of immunized persons. Severe reactions are uncommon, consisting of wheezing or urticaria in an estimated 1.0 per 1 million doses, or anaphylaxis in $<1.0$ per 1 million doses. There are also rare reports of Guillain-Barré syndrome or other neurologic disorders such as optic neuritis, paresthesia, or convulsions with onset temporally associated with vaccination. In most of the reported instances, multiple injections of different vaccines were given to the patients, so the role of meningococcal vaccination is uncertain. ${ }^{65,66}$

The main disadvantages of serogroup $\mathrm{C}$ polysaccharide vaccines are the limited or lack of immune response in young children and that there is no durable immunologic memory: they do not stimulate $\mathrm{T}$ lymphocytes or induce immunologic memory. ${ }^{66}$ Serum antibody levels decline significantly in infants and children under 5 years of age, but in healthy adults antibodies can still be detected after 10 years. However, clinical protection wanes over time in all age groups. ${ }^{2,64,66,67}$ Additionally, those vaccines have no or limited impact on nasopharyngeal carriage and, therefore, do not appear to contribute to herd immunity. ${ }^{65}$

The immunogenicity of serogroup $\mathrm{C}$ polysaccharide vaccines is age related, because the bactericidal activity of antibodies elicited by vaccination in children aged from 
18 months to 5 years may be disproportionately lower than that elicited in older children and adults ${ }^{68,69}$ and may decline to baseline within 1 year. ${ }^{70}$ The induction of immune hyporesponsiveness to a subsequent exposure to serogroup $\mathrm{C}$ polysaccharide has been observed in studies of immunized infants, ${ }^{70}$ toddlers, ${ }^{71,72}$ and adults. ${ }^{73-75}$

The effectiveness of serogroup $C$ polysaccharide vaccines in young children during a major group C epidemic in São Paulo $^{76}$ was $12 \%$ (95\% confidence interval $(\mathrm{CI})$ : $\left.-55,62\right)$ for children aged 2 years, but it was $83 \%$ among US military recruits at high risk of acquiring MD. ${ }^{77}$

On the other hand, the effectiveness of serogroup $\mathrm{C}$ polysaccharide vaccines estimated as part of postlicensure studies in Gregg County, Texas, was $85 \%$ among persons aged 2-29 years (95\% CI: 27, 97) and 93\% for children aged 2-5 years (95\% CI: 12, 99). ${ }^{78}$ In Quebec, Canada, after 1.6 million of doses administered to persons aged between 6 months and 20 years, vaccine effectiveness estimated for children under the age of 2 years was negative; for children aged 2-9 years, vaccine effectiveness was 41\% (95\% CI: -106, 79). Among persons aged 5-20 years, during the first 2 years of follow-up, efficacy was $65 \%$ (95\% CI: 20,84$)$, but it dropped to $0 \%$ between 3 and 5 years after vaccination $(95 \% \mathrm{CI}:-5,65) .{ }^{79}$

\section{Conjugate serogroup $C$ vaccines}

Conjugate serogroup $\mathrm{C}$ vaccines were introduced at the end of the 1990s and represent a major advance compared with plain polysaccharide vaccines, overcoming the shortcomings of these vaccines by converting the polysaccharide into a T-celldependent antigen. They were developed by covalently binding highly immunogenic protein carriers to saccharide antigens (Table 1). This technique improves immunogenicity in infants (the age group with the highest incidence rates of MD), stimulates immunologic memory, provides longer effects, does not lead to hyporesponsiveness with repeated dosing, and can decrease acquisition of nasopharyngeal carriage, thereby possibly inducing herd immunity. ${ }^{67}$

With regard to prior polysaccharide vaccination effect on antibody response, it was noted that titer, serum bactericidal antibody response and duration was lower in the adults who were vaccinated previously with plain serogroup $\mathrm{C}$ polysaccharide vaccine. ${ }^{80,81}$

In the UK, prelicensure safety studies of conjugate serogroup $\mathrm{C}$ vaccines reveal transient headache of mild to moderate severity as the most commonly reported adverse event, with the highest rate $(12 \%)$ in the first 3 days after vaccination. Headache was reported more frequently in secondary school than in primary school children, and more frequently in girls than in boys. Local reactions at the injection site consisted mostly of pain, tenderness, and occasional redness. These tended to be of mild to moderate severity, were maximal on the third postvaccination day, and typically resolved within a day. Local reactions were more common after diphtheria toxoid or diphtheria toxoid-tetanus toxoid booster vaccination than conjugate serogroup $C$ vaccination. Preexisting allergies did not appear to affect reactogenicity. ${ }^{82}$ Postlicensure passive surveillance through reports of adverse vaccine events from health professionals to the UK Medicines Control Agency/Committee on Safety of Medicines indicated a rate of one adverse event per 2875 doses of conjugate serogroup $\mathrm{C}$ vaccines which consisted of transient headache, pyrexia, dizziness, or local reaction. Anaphylaxis was reported at a rate of one per 500,000 doses distributed. While some new reactions to conjugate serogroup $\mathrm{C}$ vaccines were identified (such as headache, nausea, vomiting, abdominal pain, and malaise in all age groups), these were generally not serious and the risk-benefit analysis was overwhelming. ${ }^{64}$

In November 1999, conjugate serogroup $C$ vaccination was introduced in the UK for infants and 15- to 17-year-olds, the two age groups with the highest risk of mortality from MDC. The adolescents were given one dose and the infants were given three doses at 2, 3, and 4 months of age along with their routine primary immunization. From mid-January 2000 onward, catch-up immunization was done with two doses in infants aged 5-11 months and one dose in toddlers aged 12-23 months. Vaccination of 2- to 14-year-olds with a single dose was completed by late $2000 .{ }^{52}$ Population-based active surveillance monitored age-specific and capsular group-specific incidences of disease and estimated vaccine coverage. Within 12-18 months after introduction of group $\mathrm{C}$ vaccination, there was a marked decline in the number of cases and number of deaths caused by MDC in the age groups targeted for immunization. ${ }^{52,83}$ For all vaccinated groups, vaccine effectiveness was $90 \%$ during the first year, but it had declined by $1-4$ years after vaccination. ${ }^{52,83}$ This was more marked in infant than in toddlers. Toddlers, with one dose, showed effectiveness of $61 \%(95 \% \mathrm{CI}:-327,94) .{ }^{84}$ So far, the magnitude of the loss of protection in children and toddlers at 1-4 years after immunization is uncertain.

In 1995 an increase of the MDC incidence associated with phenotype C:2b:P1.2.5 was observed in Spain. As a public health response to this, a mass vaccination campaign with polysaccharide vaccine was initiated in most of the country (1996-1997), reducing the number of cases caused by this serogroup. ${ }^{85,86}$ Two years after the mass vaccination campaign, 
effectiveness began to decrease, with the number of cases rising in all age groups. As a result, the health authorities decided to include the new and available meningococcal $\mathrm{C}$ conjugate vaccine in the routine vaccination schedule by September 2000, as well as carrying out a mass vaccination campaign ${ }^{86}$ achieving a significant decrease of MDC incidence. ${ }^{85}$ Vaccine effectiveness estimates of $98 \%$ (95\% CI: $96,98)$ declined to $78 \%$ (95\% CI: 3, 95) beyond 1 year. $^{87}$ Postvaccination monitoring of both epidemiological evolution of MD and long-term effects, show cases caused by B:2a:P1.5 probably originated from virulent strain C:2a:P1.5, suggesting that capsular switching by exchange of genetic material encoding the polysaccharide capsule might have occurred. $^{85}$

The Netherlands commenced immunization in 2002 with a single dose at 14 months of age, with a catch-up campaign from 1 to 19 years of age up to April 2006. No vaccine failures were detected, and the number of MDC cases declined from 276 in 2001 to only four in $2005 .^{88}$ The decrease was observed even in those not targeted, and data were consistent with induction of herd immunity.

Control of disease may be more dependent on decrease carriage in the population and herd immunity generated by catch-up campaigns than of persistence of protective immunity provided by vaccine. Effectiveness on decreasing meningococcal carriage after 1 year was $66 \%$, and there was no evidence of increase in carriage in other capsular groups ${ }^{89,90}$ For countries using conjugate serogroup C vaccines, close surveillance of replacement and capsular switching from $\mathrm{C}$ to $\mathrm{B}$ is required. ${ }^{91}$ Those concerns were not detected in the UK..$^{92,93}$

In 2005, a quadrivalent meningococcal conjugate vaccine (MCV4) for serogroups A, C, W-135, and Y (Menactra ${ }^{\circledR}$, Sanofi Pasteur, referred to herein as MCV4) was licensed in the United States for persons aged $11-55$ years. ${ }^{94-96}$ As was the case with the monovalent serogroup $\mathrm{C}$ conjugate vaccines, the low incidence of MD in North America and Europe precluded performing an efficacy trial, and efficacy of the MCV4 vaccine was inferred from immunogenicity data. In these studies, MCV4 vaccine elicited noninferior serum bactericidal antibody responses as compared with the respective responses of controls given the US-licensed meningococcal quadrivalent polysaccharide vaccine (MPSV4). ${ }^{97,98}$ For both vaccines, $97 \%-100 \%$ of subjects achieved serum bactericidal titers against all four capsular groups. In prelicensure studies, MCV4 vaccine was safe and well tolerated. ${ }^{96,97,99}$ In randomized studies, low-grade fevers $\left(\geq 38^{\circ} \mathrm{C}\right)$ were more common after MCV4 than MPSV4 vaccination $(5.1 \%$ versus $3.0 \%$, respectively, in immunized adolescents, $P<0.05 ; 1.5 \%$ versus $0.5 \%$ in adults $P<0.05$ ). Less than $5 \%$ of MCV4- or MPSV4-vaccinated subjects experienced serious systemic reactions (defined as high fevers; or headache, fatigue, malaise, chills or arthralgia requiring bed rest; or anorexia; or three or more episodes of vomiting; or five or more episodes of diarrhea; or the presence of rash or seizures). Local reactions were more common after MCV4 than MPSV4 vaccination, which likely reflects the presence of diphtheria toxoid as the carrier. ${ }^{96,97,99}$

In postlicensure observations, adverse reactions to MCV4 or MPSV4 vaccines are mild and fever is infrequent. No adverse effects have been documented among women vaccinated with MPSV4 during pregnancy or among their newborns. There are no data available on the use of MCV4. ${ }^{99-102}$ Both vaccines can be administered during a minor acute illness, even in the presence of low-grade fever. Individuals sensitive to thimerosal (mercury) should receive preservative-free MPSV4 or MCV4 vaccines supplied in the single-dose preparations. Both vaccines are contraindicated in persons with known hypersensitivity to any vaccine component or to dry natural rubber latex. MPSV4 can be given together with other vaccines but it should be administered at a different site of injection and with a different syringe. ${ }^{96,97,99}$

\section{Immunization program: strategy, dosing, and schedule}

Disease caused by N. meningitidis has been historically addressed using polysaccharide vaccines against the four major serogroups: A, C, Y, and W-135. With few exceptions, polysaccharide vaccines have not been used in routine schedules because of perceived limitations of the duration of effectiveness, especially when administered during infancy. Given the sporadic nature of outbreaks, the optimal use of these vaccines to control both short-term epidemic and endemic disease has been the subject of much debate. ${ }^{103}$ While developed countries have concentrated on outbreak control with mass vaccination strategies or prophylactic use for travelers, a number of countries have effectively reduced disease burden with routine vaccination or at school entry with serogroup AC polysaccharide vaccine..$^{53,104}$

When deciding to implement a mass vaccination campaign to prevent MDC, one must consider whether the cases represent an outbreak or an unusual clustering of endemic cases. Mass vaccination programs are expensive, they require considerable public health effort, and they may create excessive concern among the public. Because the number of cases in outbreaks is 
usually not substantial, this determination requires evaluation and analysis of the patterns of disease occurrence. ${ }^{105}$

An outbreak has been defined by the Centers for Disease Control and Prevention as the occurrence of three or more cases in less than 3 months, resulting in a primary disease attack rate of at least ten cases per 100,000 in persons who have a common affiliation or who live in the same area but have no close contact. ${ }^{106}$ Outbreaks of MD have occurred in organizations and communities. Mass vaccination programs to control outbreaks were an option for management of clusters of cases in the United States. Either MCV4 or MPSV4 can be used for control of outbreaks caused by a strain with a vaccine-preventable capsular group. ${ }^{73,97,106}$

Two MCV4s (Menactra, Sanofi Pasteur; Menveo ${ }^{\circledR}$, Novartis) are licensed for use in the United States. Both vaccines are licensed for persons aged 2-55 years. These vaccines are the preferred vaccine for people aged 2-55 years; meningococcal polysaccharide vaccine should for people over the age of 55 years. Approximately 7-10 days are required after vaccination for development of protective levels of antibody. ${ }^{107}$

The Advisory Committee on Immunization Practices (ACIP) recommends routine vaccination of persons with MCV4 at the age of 11 or 12 years, followed by a booster dose at the age of 16 years. For adolescents who receive the first dose at 13-15 years of age, a one-time booster dose should be administered, preferably at 16-18 years of age. Persons who receive their first dose of MCV4 at 16 years of age or older do not need a booster dose, unless they remain at increased risk for MD. Routine vaccination of healthy persons who are not at increased risk for exposure to $N$. meningitidis is not recommended after 21 years of age. ${ }^{107}$

Revaccination is indicated for persons who have received MPSV4 and who remain at high risk of MD. ${ }^{96}$ Also, persons previously vaccinated with either MCV4 or MPSV4 who are at prolonged increased risk for MD should be revaccinated with MCV4. ${ }^{107}$

For children who receive MPSV4 when they are under the age of 4 years, the ACIP recommends that revaccination be considered 2-3 years later. In addition, the ACIP recommends that older children and adults be considered for revaccination after 3-5 years. The ACIP recommends that revaccination of persons outside the 11- to 55-year-old age range should be with MPSV4. ${ }^{107}$

Data indicate that the immune response to a single dose of MCV4 is not sufficient in persons with certain medical conditions. Persons with persistent complement component deficiencies or asplenia should receive a two-dose primary series administered 2 months apart and then receive a booster dose every 5 years. Adolescents aged 11-18 years with human immunodeficiency virus infection should be routinely vaccinated with a two-dose primary series. Other persons with human immunodeficiency virus who are vaccinated should receive a two-dose primary series administered 2 months apart. All other persons at increased risk for MD (Table 2) should receive a single dose. Persons previously vaccinated with a single dose at 7 years of age or older and who are at prolonged increased risk should be revaccinated 5 years after their previous meningococcal vaccine. Persons who previously were vaccinated with a single dose at ages 2-6 years and are at prolonged increased risk should be revaccinated 3 years after their previous meningococcal vaccine. ${ }^{107}$

\section{Public health approaches to patients}

The function of local public health agencies is assessment, assurance, and policy development to promote and protect the health of the public. Accessibility to health services is critical to guarantee timely medical attention, especially in life-threatening diseases like MD. In most developing countries, health facilities lack material, drugs, and laboratory equipment and therefore medical attention is poor, in contrast to high-income countries, where medical attention is of a high quality and is accessible to the majority of the population.

MD is a compulsory notifiable disease in most countries. Notification procedures must be based on the use of a standard case definition for meningococcal meningitis, with three recommended levels of diagnosis: suspected, probable, or confirmed. ${ }^{110}$ Clinicians and laboratory staff should notify patients rapidly, by phone or fax, to start contact tracing. Chemoprophylaxis can be instituted promptly.

As contagiousness of patients is moderate and disappears quickly following antimicrobial treatment, isolation

Table 2 High-risk groups recommended for vaccination ${ }^{5,108,109}$

\begin{tabular}{ll}
\hline 1 & College freshmen living in dormitories \\
2 & $\begin{array}{l}\text { Microbiologists who are routinely exposed to } \\
\text { isolates of Neisseria meningitidis }\end{array}$ \\
3 & Military recruits \\
4 & $\begin{array}{l}\text { Persons who travel to or reside in countries } \\
\text { where meningococcal disease is hyperendemic } \\
\text { or epidemic, particularly if contact with the local } \\
5\end{array}$ \\
& $\begin{array}{l}\text { Population will be prolonged } \\
\text { Persistent complement component deficiencies } \\
\text { (eg, C5-C9, properdin, factor H, or factor D) } \\
\text { People who have anatomic or functional asplenia }\end{array}$ \\
\hline
\end{tabular}


of the patient is not necessary. Nevertheless, some restriction measures are recommended, such as respiratory isolation and excluding the patient from school/institution/ work until 24 hours of an appropriate course of clearance antibiotic is completed.

Health education for the patient, members of the family, and the public is also an important concern. The patient and their contacts should be advised about the nature of the infection by explaining the main signs, symptoms, severity, and mode of transmission of disease, stressing the importance of treatment, vaccination, and other preventive and control measures.

In $\mathrm{MD}$, the challenge for healthcare practitioners is to identify timely those patients who will progress from a nonspecific early presentation to severe disease, particularly since the early symptoms and signs may be indistinguishable from intercurrent and self-limiting viral infection. ${ }^{11}$ The majority of deaths may occur in the first 24 hours, frequently before the institution of specialized care. ${ }^{112}$

Current expert advice endorses the importance of effective meningococcal infection management based on early recognition, prompt antibiotic treatment, and speedy referral to hospital for all suspected cases.

If the patient is a presumptive case of MD, the case should be classified as high priority for assessment and review by the medical staff and seen urgently and receive his first dose of antibiotics as soon as possible. ${ }^{60}$ If a general practitioner (GP) decides that a patient with a nonspecific febrile illness does not require referral to a hospital, the patient must be under frequent and regular review, looking for clinical changes. If the patient subsequently develops a rash or deteriorates in any way, the GP should be advised or the patient immediately referred to a hospital emergency department. ${ }^{113}$ The GP should arrange urgent transfer of the patient to the appropriate hospital, preferably by ambulance, with paramedics experienced in managing critically ill patients. ${ }^{60} \mathrm{MD}$ is a potentially fatal disease; it should always be viewed as a medical emergency and it should be managed, without exception, in intensive care units.

\section{Diagnosis \\ Clinical findings}

Meningococcal infection most commonly presents as either meningitis or septicemia, or a combination of both. Less commonly, individuals may present other clinical features. ${ }^{5}$

Septicemia (also known as meningococcemia), with or without meningitis, can be particularly severe and has a fulminant and rapidly fatal course, causing MD to be a much-feared disease. ${ }^{114}$ The most characteristic feature of meningococcemia is a hemorrhagic (ie, petechial or purpuric) rash that does not blanch under pressure. However, a rash is not always present. ${ }^{115}$ Careful attention to associated manifestations such as shock and coagulopathy is critical. In nearly all patients who develop shock, and in most patients with meningitis, the beginning of the bacteremic phase is marked by the onset of chills, acute fever, lower back pain, thigh pain, or generalized muscle aches. Within a few hours, purpura fulminans may develop without signs of meningitis ${ }^{116}$ and it is often associated with the rapid onset of hypotension, acute adrenal hemorrhage (the Waterhouse-Friderichsen syndrome), and multiorgan failure. ${ }^{5}$ In children, nonspecific symptoms such as fever, drowsiness, nausea and vomiting, irritability, and poor feeding are present within 4-6 hours from the onset of the disease. ${ }^{6,111}$ The classic, rapidly evolving purpuric rash associated with MD and neck pain, or stiffness, usually develops after 12 hours.

Meningitis signs and symptoms depend on the age of the patient, the duration of illness, and the host response to infection. The clinical features of meningococcal meningitis in infants and children can be subtle, variable, nonspecific, or even absent. In infants, they may include hypothermia, lethargy, irritability, poor feeding, vomiting, respiratory distress, seizures, or bulging fontanelles. ${ }^{117}$ Unfortunately, most cases of MD are diagnosed after the appearance of these late signs, and it is not infrequent for children who are admitted to hospital to have been initially misdiagnosed. ${ }^{111}$

\section{Laboratory findings}

All patients with suspected meningococcal infection should have blood and CSF collected for Gram stain and culture. Aspirate or biopsy of petechiae or other skin lesions should also be done. PCR testing of blood (and CSF if meningitis is present) should be considered part of the routine diagnostic. Nevertheless, the classic laboratory diagnosis of MD has relied on bacteriologic culture, but the sensitivity of culture may be low, especially when performed after the initiation of antibiotic treatment.

Since CSF examination is of paramount importance for the diagnosis of meningococcal meningitis, lumbar puncture is essential. ${ }^{110} \mathrm{CSF}$ is usually turbid or purulent (but may occasionally be clear or bloody). Basic routine examination feasible in most laboratories consists of measurement of the white blood cell count (usually above 1000 cells $/ \mathrm{mm}^{3}$ with $>60 \%$ polymorphonuclears; measurement of protein level: $>0.80 \mathrm{~g} / \mathrm{L}$ and Gram stain, showing intra- or extracellular Gram-negative diplococci. 
Diagnosis is confirmed by the isolation of $N$. meningitidis, the demonstration of Gram-negative diplococci, or the detection of meningococcal antigen in CSF, blood, or other normally sterile site. ${ }^{110}$ PCR analysis offers the advantages of detecting serogroup-specific $N$. meningitidis DNA and of not requiring live organisms for a positive result. ${ }^{5}$

CSF culture can be negative in patients who receive antibiotic treatment before CSF examination. ${ }^{118}$ In such patients, increased white blood cell counts and protein concentration in CSF are usually sufficient to establish presumptive diagnosis. Blood cultures or non-culture diagnostic tests may help in identifying the infecting pathogen, especially in septicemia. Non-culture tests should be considered for patients who need earlier identification of pathogens, who have previously received antibiotics, or whose initial CSF Gram stain is negative. Such tests mainly include latex agglutination, PCR, loop-mediated isothermal amplification method, microarray or biochip, and immunochromatography. ${ }^{118}$

\section{Treatment}

\section{Timing}

In MD, the speed with which treatment is initiated, antibiotics are administered, and complications of shock and multiorgan failure are treated is a major determinant of outcome. The duration of delay in initiating antibiotic therapy after hospital admission and suboptimal health care delivery has been directly associated with poor outcome. ${ }^{119-121}$

\section{Intensive care management}

The primary goals of therapy in the first hours following clinical presentation are to maintain oxygenation and ventilation and to achieve normal tissue perfusion. Early semielective intubation and positive-pressure mechanical ventilatory support should be strongly considered in this setting. Circulation is the next target to assess and manage. ${ }^{122}$ In addition, myocardial support with inotropes is frequently necessary to maintain end organ perfusion in more severely ill patients. ${ }^{123}$ An increasingly recognized approach is an effort to rapidly stabilize the hemodynamics using early goal-directed therapy. ${ }^{122}$ In adults, early goal-directed therapy aims at achieving adequate central venous pressure, mean arterial pressure, urine output, and central venous oxygenation within 6 hours. ${ }^{124}$ Dopamine remains the most common first choice of inotropic agents for patients with fluid-refractory shock, but both reported and theoretical adverse effects include functional suppression of neutrophils by attenuating the chemoattractant effect of interleukin-8 and interference with the neuroendocrine system by suppressing the release of many anterior pituitary hormones, including growth hormone, thyroid-stimulating hormone, and prolactin, aggravating immune dysfunction and increasing susceptibility to infection. ${ }^{125,126}$ Therefore, clinicians are increasingly choosing low-dose epinephrine to achieve beta-adrenergic-mediated inotropic support as a firstline therapy for fluid refractory shock. Epinephrine stimulates gluconeogenesis and glycogenolysis and inhibits the action of insulin, leading to an adverse profile of dysregulated serum glucose also increasing the production of lactate, independent of organ perfusion. Other inotropic agents used are milrinone and vasopressin. ${ }^{122}$

It is important to note that resuscitation end points targeted in resource-rich health care environments are not available to intensive care personnel in many developing parts of the world. As a result, these practitioners rely on clinical therapeutic end points: normalization of heart rate, capillary refill time $<2$ seconds, strong peripheral pulses, warm extremities, normal blood pressure, return to baseline mental status and normal respiratory rate. ${ }^{122}$ In severe MD, microthrombosis and hypoperfusion can lead to extensive purpura (mainly in limbs or skin) that can become necrotic. Extensive necrotic areas can consume clotting factors, worsen any coagulopathy, and serve as reservoir for bacteria, leading to prolonged bacteremia. ${ }^{6}$

Early fluid resuscitation is associated with improved survival. ${ }^{123}$ In the intensive care unit, large amounts of fluids may be required during the first days of care, and vasoactive drug infusions are often needed. Coagulopathy is frequent, but it has no specific treatment. The use of colloids and steroids may be beneficial, but other new therapies such as insulin and activated protein $\mathrm{C}$ still need to be studied further. When present, cerebral edema and altered cerebral blood flow are the main concerns; the use of osmolar solutions may be necessary, but the main therapeutic intervention is to ensure adequate blood pressure for adequate cerebral perfusion. Seizures and hyponatremia should be aggressively treated. ${ }^{6}$

\section{Choice of antimicrobials}

Antibiotics are considered a cornerstone of MD treatment and must be instituted as soon as possible. In patients with suspected meningococcal meningitis for whom immediate lumbar puncture is delayed because of pending brain imaging study or the presence of disseminated intravascular coagulation, blood cultures must be obtained and empirical antimicrobial treatment should be initiated immediately with parenteral antibiotics (either benzylpenicillin or cefotaxime). ${ }^{118,127}$ 
The choice of which antibiotic to use should be made based on local antibiotic resistance and availability. Many antimicrobials are active against meningococci in vitro, but only those that penetrate sufficiently the cerebrospinal space and are affordable should be used. Either parenteral ampicillin or penicillin is the drug of choice. ${ }^{6,111}$ Chloramphenicol is a good and inexpensive alternative. Third-generation cephalosporins (ceftriaxone and cefotaxime) are excellent alternatives, but they are considerably more expensive. Although oral cotrimoxazole (trimethoprim-sulfamethoxazole) is inexpensive and has good CSF penetration, sulfa-resistant strains have become common and sulfa drugs are not recommended unless sulfa-sensitivity testing has been done. In unfavorable conditions, the drug of choice is oily chloramphenicol. ${ }^{110}$

\section{Route of administration}

The intravenous route is recommended. However, a series of clinical studies have shown the use of intramuscular chloramphenicol in oil to be as effective as intravenous ampicillin for MD. ${ }^{110}$

\section{Duration of antibiotic therapy}

A 7-day course is still the rule for the treatment of MD (beyond the neonatal period) in most high-income countries. ${ }^{110}$ However, there is good evidence that for meningococcal meningitis a 3- or 4-day course of benzylpenicillin is as effective as any longer course of antimicrobials. ${ }^{128}$ The long-acting form of chloramphenicol has also been shown to be effective. ${ }^{110}$

As well as antibiotics, high-level intensive care supportive therapy should be used where medically appropriate. Particular attention should be paid to maintenance of blood pressure and tissue perfusion and management of cerebral edema. Patients may require artificial ventilation and other forms of support for prolonged periods, and the complications of the coagulopathy, or intravascular coagulation abnormalities, may be severe. ${ }^{60}$

Although patients with MD are not efficient transmitters of meningococci, the failure to administer appropriate clearance antibiotics in patients treated with penicillin is not acceptable, and the public health response should include advice to treating physicians on the use of clearance antibiotics when appropriate. ${ }^{96}$

\section{Adjunctive treatment}

The beneficial effect of adjunctive dexamethasone treatment has been reported by various authors. ${ }^{129}$ In a 2007 Cochrane review, adjunctive treatment with dexamethasone was associated with lower case mortality, and lower rates of severe hearing loss and long-term neurological sequelae, but concerns have been expressed about reducing blood-brain permeability and thereby the penetration of antibiotics in the subarachnoid space. ${ }^{130}$ The use of steroids in the treatment of MD is still controversial and remains a topic of debate.

\section{Physical sequelae}

Improvement in intensive care and supportive therapy, increased the number of survivors of MDC that may subsequently suffer from severe physical sequelae. Affected patients need long-term multidisciplinary rehabilitation, as there can be a significant reduction in functional ability and quality of life..$^{10,131,132}$ The severity of invasive disease and physical disability may be greater in patients with MDC than in those with MD caused by serogroup B. ${ }^{10,132-135}$

In cases with septicemia and peripheral ischemia, surgical management should be carried out immediately. Early microsurgical arteriolysis is a reliable method for reducing the number of devastating amputations normally found in some patients with meningococcal sepsis. This significantly improves the functional outcome in severely ischemic limbs. ${ }^{136}$ When there is peripheral ischemia in the presence of raised pressures in the lower limb, fasciotomy is indicated if the rash has been present for less than 24 hours and there is no contraindication such as excessive bleeding. Amputation should be delayed since the end result may not be predictable (at initial presentation) and should be carried out as an elective procedure with the aim of giving the child a stump for life. It should be carefully planned and expertly carried out. ${ }^{137}$

\section{Conclusion and future directions}

Worldwide, MDC continues to be an important cause of morbidity, mortality, and neurological sequelae and it continues to require high levels of public health spending. Each country should determine the measures most adequate to prevent and control the disease according to that country's epidemiology, the most feasible public health approaches, and the existing economic support. The health policy in each country should consider current behavior of disease, immunogenicity and antibody protection persistence in high-risk groups after immunization, vaccine effectiveness, and the costs and benefits of different strategies. Improvement of surveillance to monitor changes in disease epidemiology and to evaluate the impact of available and future vaccines is essential. 


\section{Disclosure}

The authors report no conflicts of interest in this work.

\section{References}

1. Harrison LH, Trotter CL, Ramsay ME. Global epidemiology of meningococcal disease. Vaccine. 2009;27 Suppl 2:B51-B63.

2. Harrison LH. Prospects for vaccine prevention of meningococcal infection. Clin Microbiol Rev. 2006;19(1):142-164.

3. Granoff DM, Harrison LH, Borrow R. Meningococcal vaccines. In: Plotkin S, Orenstein WA, Offit PA, editors. Vaccines. 5th ed. Philadelphia (PA): Saunders Elsevier; 2008:399-434.

4. Harrison LH, Broome CV. The epidemiology of meningococcal meningitis in the US civilian population. In: Vedros NA, editor. Evolution of Meningococcal Disease. Vol 1. Boca Raton (FL): CRC Press; 1987:27-45.

5. Rosenstein NE, Perkins BA, Stephens DS, Popovic T, Hughes JM. Meningococcal disease. N Engl J Med. 2001;344(18):1378-1388.

6. Branco RG, Amoretti CF, Tasker RC. Meningococcal disease and meningitis. J Pediatr (Rio J). 2007;83(2 Suppl):S46-S53.

7. World Health Organization. Wkly Epidemiol Rec [serial on the Internet]. 2002 [cited 2011 Aug 10]. Available from: http://www.who. int/immunization/wer7740meningococcalOct02positionpaper.pdf. Accessed August 24, 2010.

8. Stephens DS, Greenwood B, Brandtzaeg P. Epidemic meningitis, meningococcemia, and Neisseria meningitidis. Lancet. 2007;369(9580): 2196-2210.

9. Fellick JM, Sills JA, Marzouk O, Hart CA, Cooke RW, Thomson AP. Neurodevelopmental outcome in meningococcal disease: a case-control study. Arch Dis Child. 2001;85(1):6-11.

10. Erickson LJ, De Wals P, McMahon J, Heim S. Complications of meningococcal disease in college students. Clin Infect Dis. 2001;33(5):737-739.

11. Kaplan SL, Schutze GE, Leake JA, et al. Multicenter surveillance of invasive meningococcal infections in children. Pediatrics. 2006;118(4):e979-e984.

12. Harrison LH. Epidemiological profile of meningococcal disease in the United States. Clin Infect Dis. 2010;50 Suppl 2:S37-S44.

13. Harrison LH, Pelton SI, Wilder-Smith A, et al. The Global Meningococcal Initiative: recommendations for reducing the global burden of meningococcal disease. Vaccine. 2011;29(18):3363-3371.

14. Cohn AC, MacNeil JR, Harrison LH, et al. Changes in Neisseria meningitidis disease epidemiology in the United States, 1998-2007: implications for prevention of meningococcal disease. Clin Infect Dis. 2010;50(2):184-191.

15. Almeida-González L, Franco-Paredes C, Pérez LF, Santos-Preciado JI. Meningococcal disease caused by Neisseria meningitidis: epidemiological, clinical, and preventive perspectives. Salud Publica Mex. 2004;46(5):438-450. Spanish.

16. Campbell H, Borrow B, Salisbury D, Miller E. Meningococcal $\mathrm{C}$ conjugate vaccine: the experience in England and Wales. Vaccine. 2009;27 Supp1 2:B20-B29.

17. Vyse A, Wolter JM, Chen J, Ng T, Soriano-Gabarro M. Meningococcal disease in Asia: an under-recognized public health burden. Epidemiol Infect. 2011;139:967-985.

18. World Health Organization. Department of Communicable Disease Surveillance and Response. WHO report on global surveillance of epidemic-prone infectious diseases. WHO/CDS/CSR/ ISR/2000.1. [serial on the Internet]. Geneva: WHO; 2000. Chapter 5: Meningococcal disease. Available from: http://www.who.int/entity/ csr/resources/publications/surveillance/Meningitis.pdf. Accessed August 1, 2011.

19. World Health Organization. WHO recommended surveillance standards [serial on the Internet]. Geneva: WHO; 1999. Available from: http:// www.who.int/csr/resources/publications/surveillance/whocdscsrisr992. pdf. Accessed May 14, 2011.
20. Nelson KE, Sifakis F. Surveillance. In: Nelson KE, Masters Williams C, editors. Infectious Disease Epidemiology: Theory and Practice. 2nd ed. Sudbury (MA): Jones and Bartlett; 2007.

21. Outbreak news. Meningococcal disease, Burkina Faso update. Wkly Epidemiol Rec. 2007;82(17):141.

22. Corless CE, Guiver M, Borrow R, Edwards-Jones V, Fox AJ, Kaczmarski EB. Simultaneous detection of Neisseria meningitidis, Haemophilus influenzae, and Streptococcus pneumoniae in suspected cases of meningitis and septicemia using real-time PCR. J Clin Microbiol. 2001;39(4):1553-1558.

23. World Health Organization. Control of Epidemic Meningococcal Disease. WHO Practical Guidelines. 2nd ed. Geneva: WHO; 1999.

24. Chanteau S, Sidikou F, Djibo S, Moussa A, Mindadou H, Boisier P. Scaling up of PCR-based surveillance of bacterial meningitis in the African meningitis belt: indisputable benefits of multiplex PCR assay in Niger. Trans $R$ Soc Trop Med Hyg. 2006;100(7): $677-680$.

25. New Jersey Department of Health and Senior Services. Meningococcal Infection, Invasive. Trenton (NJ): New Jersey Department of Health and Senior Services; 2008. Available from: http://nj.gov/health/cd/documents/ chapters/meningococcal_ch.pdf. Accessed August 1, 2011.

26. Stephens DS. Biology and pathogenesis of the evolutionarily successful, obligate human bacterium Neisseria meningitidis. Vaccine. 2009;27 Suppl 2:B71-B77.

27. Molesworth AM, Cuevas LE, Connor SJ, Morse AP, Thomson MC. Environmental risk and meningitis epidemics in Africa. Emerg Infect Dis. 2003;9(10):1287-1293.

28. Zughaier SM, Tzeng YL, Zimmer SM, Datta A, Carlson RW, Stephens DS. Neisseria meningitidis lipooligosaccharide structuredependent activation of the macrophage CD14/Toll-like receptor 4 pathway. Infect Immun. 2004;72(1):371-380.

29. Moore PS, Hierholzer J, DeWitt W, et al. Respiratory viruses and mycoplasma as cofactors for epidemic group A meningococcal meningitis. JAMA. 1990;264(10):1271-1275.

30. Hibberd ML, Sumiya M, Summerfield JA, Booy R, Levin M. Association of variants of the gene for mannose-binding lectin with susceptibility to meningococcal disease. Lancet. 1999;353(9158):1049-1053.

31. Tsang RS, Squires SG, Tam TW. Characterization of Neisseria meningitidis strains isolated from invasive meningococcal disease cases in Canada in 2001. Can J Microbiol. 2003;49(10):633-638.

32. Sáfadi MA, Cintra OA. Epidemiology of meningococcal disease in Latin America: current situation and opportunities for prevention. Neurol Res. 2010;32(3):263-271.

33. Gabastou JM, Agudelo CI, Brandileone MC, et al. Characterization of invasive isolates of S. pneumoniae, H. influenzae, and N. meningitidis in Latin America and the Caribbean: SIREVA II, 2000-2005. Rev Panam Salud Publica. 2008;24(1):1-15. Spanish.

34. EU-IBIS Network. Invasive Neisseria meningitidis in Europe. London: Health Protection Agency; 2006.

35. Mendsaikhan J, Watt JP, Mansoor O, et al. Childhood bacterial meningitis in Ulaanbaatar, Mongolia, 2002-2004. Clin Infect Dis. 2009; 48 Suppl 2:S141-S146.

36. Ni JD, Jin YH, Dai B, et al. Recent epidemiological changes in meningococcal disease may be due to the displacement of serogroup A by serogroup C in Hefei City, China. Postgrad Med J. 2008;84(988): 87-92.

37. Whalen CM, Hockin JC, Ryan A, Ashton F. The changing epidemiology of invasive meningococcal disease in Canada, 1985 through 1992: emergence of a virulent clone of Neisseria meningitidis. JAMA. 1995; 273(5):390-394.

38. Ashton FE, Ryan JA, Borczyk A, Caugant DA, Mancino L, Huang D. Emergence of a virulent clone of Neisseria meningitidis serotype $2 \mathrm{a}$ that is associated with meningococcal group C disease in Canada. J Clin Microbiol. 1991;29(11):2489-2493.

39. World Health Organization. Meningococcal meningitis. Fact sheet No. 141. Geneva: WHO; 2011. Available from: http://www.who.int/ mediacentre/factsheets/fs141/en/. Accessed August 19, 2011. 
40. Tully J, Viner RM, Coen PG, et al. Risk and protective factors for meningococcal disease in adolescents: matched cohort study. BMJ. 2006;332(7539):445-450.

41. Frosch M, Maiden MCJ, editors. Handbook of Meningococcal Disease: Infection Biology, Vaccination, Clinical Management. 2nd ed. Weinheim: Wiley-VCH Verlag GmbH \& Co KGaA; 2006.

42. Coen PG, Tully J, Stuart JM, Ashby D, Viner RM, Booy R. Is it exposure to cigarette smoke or to smokers which increases the risk of meningococcal disease in teenagers? Int J Epidemiol. 2006;35(2): 330-336.

43. Booy R, El Bashir H, Rashid H, Shingadia D, Haworth E. Influenza and meningococcal disease: lessons for travellers and government from 2 epidemic diseases. Travel Med Infect Dis. 2009;7(4):253-256.

44. Edmunds WJ, Medley GF, Nokes DJ. Evaluating the cost-effectiveness of vaccination programmes: a dynamic perspective. Stat Med 1999;18(23):3263-3282.

45. Salisbury DM, Beverley PCL, Miller E. Vaccine programmes and policies. Br Med Bull. 2002;62:201-211.

46. Granoff DM, Harrison LH, Pelton S. Meningococcal vaccines. In: Plotkin SA, Orenstein WA, editors. Vaccines. 6th ed. Amsterdam: Saunders Elsevier; 2011.

47. World Health Organization. Position paper. WHO/VSQ/GEN/96.02. Geneva: WHO.

48. Chiappini E, Venturini E, Bonsignori F, Galli L, de Martino M. Serogroup C Neisseria meningitidis invasive infection: analysis of the possible vaccination strategies for a mass campaign. Acta Paediatr. 2010;99(11):1609-1614

49. Rodríguez AP, Dickinson F, Baly A, Martinez R. The epidemiological impact of antimeningococcal B vaccination in Cuba. Mem Inst Oswaldo Cruz. 1999;94(4):433-440.

50. EU-IBIS Network. Invasive Neisseria meningitidis in Europe 2006. London: Health Protection Agency; 2006. Available from: http:// www.hpa-bioinformatics.org.uk/euibis/documents/2006_meningo.pdf. Accessed November 8, 2010.

51. Miller E, Salisbury D, Ramsay M. Planning, registration, and implementation of an immunisation campaign against meningococcal serogroup $\mathrm{C}$ disease in the UK: a success story. Vaccine. 2001;20 Supp1 1: S58-S67.

52. De Wals P, Deceuninck G, Boulianne N, De Serres G. Effectiveness of a mass immunization campaign using serogroup $\mathrm{C}$ meningococcal conjugate vaccine. JAMA. 2004;292(20):2491-2494.

53. Sotolongo F, Campa C, Casanueva V, Fajardo EM, Cuevas IE, González N. Cuban meningococcal BC vaccine: experiences and contributions from 20 years of application. MEDICC Rev. 2007;9(1):16-22.

54. Pérez AE, Dickinson F, Llanes R. Invasive meningococcal disease: Cuba 1983-2006. Vacci Monitor. 2010;19(3):8-14.

55. Climent Y, Yero D, Martinez I, et al. Clonal distribution of diseaseassociated and healthy carrier isolates of Neisseria meningitidis between 1983 and 2005 in Cuba. J Clin Microbiol. 2010;48(3):802-810.

56. Zhang TG, He JG, He X, Chen LJ, Shao ZJ, Sun MP. The molecular characterization of serogroup $\mathrm{C}$ Neisseria meningitidis strains circulating in Beijing. J Microbiol. 2006;44(6):685-688.

57. New Zealand Ministry of Health. Meningococcal invasive disease. In: Immunisation Handbook 2011. Wellington: Ministry of Health; 2011. Available from: http://www.moh.govt.nz/moh.nsf/Files/ immunise-handbook/\$file/16MeningococcalInvDisease.pdf. Accessed October 15, 2011.

58. Gardner P. Clinical practice: prevention of meningococcal disease. N Engl J Med. 2006;355(14):1466-1473.

59. Public Health Laboratory Service; Public Health Medicine Environmental Group; Scottish Centre for Infection and Environmental Health. Guidelines for public health management of meningococcal disease in the UK. Commun Dis Public Health. 2002;5(3):187-204.

60. Australian Government Department of Health and Ageing. Guidelines for the early clinical and public health management of meningococcal disease in Australia. Australian Capital Territory: Australian Government: 2009.
61. Centers for Disease Control and Prevention. Manual for the Surveillance of Vaccine-Preventable Diseases. 4th ed. Atlanta (GA): CDC; 2008. Available from: http://www.cdc.gov/vaccines/pubs/surv-anual/meningococcaldisease.pdf. Accessed October 15, 2011.

62. Kristiansen BE, Tveten Y, Jenkins A. Which contacts of patients with meningococcal disease carry the pathogenic strain of Neisseria meningitidis? A population based study. BMJ. 1998;317(7159): 621-625.

63. Hoek MR, Christensen H, Hellenbrand W, Stefanoff P, Howitz M, Stuart JM. Effectiveness of vaccinating household contacts in addition to chemoprophylaxis after a case of meningococcal disease: a systematic review. Epidemiol Infect. 2008;136(11):1441-1447.

64. World Health Organization. WHO prequalified vaccines [search tool on the Internet]. Geneva: WHO; [updated June 22, 2011]. Available from: http://www.who.int/immunization_standards/vaccine_quality/ PQ_vaccine_list_en/en/index.html. Accessed October 19, 2011.

65. Prevention and control of meningococcal disease: recommendations of the Advisory Committee on Immunization Practices (ACIP). MMWR Recomm Rep. 2000;49(RR-7):1-10.

66. Bilukha O, Messonnier N, Fischer M. Use of meningococcal vaccines in the United States. Pediatr Infect Dis J. 2007;26(5):371-376.

67. Girard MP, Preziosi MP, Aguado MT, Kieny MP. A review of vaccine research and development: meningococcal disease. Vaccine. 2006;24(22):4692-4700.

68. Harris SL, King WJ, Ferris W, Granoff DM. Age-related disparity in functional activities of human group $\mathrm{C}$ serum anticapsular antibodies elicited by meningococcal polysaccharide vaccine. Infect Immun. 2003;71(1):275-286.

69. Campagne G, Garba A, Fabre P, et al. Safety and immunogenicity of three doses of a Neisseria meningitidis A + C diphtheria conjugate vaccine in infants from Niger. Pediatr Infect Dis J. 2000;19(2): $144-150$.

70. Espín Ríos I, García-Fulgueíras A, Navarro Alonso JA, et al. Seroconversion and duration of immunity after vaccination against group $\mathrm{C}$ meningococcal infection in young children. Vaccine. 2000;18(24):2656-2660.

71. Leach A, Twumasi PA, Kumah S, et al. Induction of immunologic memory in Gambian children by vaccination in infancy with a group A plus group $\mathrm{C}$ meningococcal polysaccharide-protein conjugate vaccine. J Infect Dis. 1997;175(1):200-204.

72. MacDonald NE, Halperin SA, Law BJ, Forrest B, Danzig LE, GranoffDM. Induction of immunologic memory by conjugated vs plain meningococcal $\mathrm{C}$ polysaccharide vaccine in toddlers: a randomized controlled trial. JAMA. 1998;280(19):1685-1689.

73. Granoff DM, Pollard AJ. Reconsideration of the use of meningococcal polysaccharide vaccine. Pediatr Infect Dis J. 2007;26(8):716-722.

74. Southern J, Deane S, Ashton L, et al. Effects of prior polysaccharide vaccination on magnitude, duration, and quality of immune responses to and safety profile of a meningococcal serogroup $\mathrm{C}$ tetanus toxoid conjugate vaccination in adults. Clin Diagn Lab Immunol. 2004;11(6):1100-1104.

75. Kawahara T, Shimizu I, Ohdan H, Zhao G, Sykes M. Differing mechanisms of early and late B cell hyporesponsiveness induced by mixed chimerism. Am J Transplant. 2005;5(12):2821-2829.

76. Taunay AE, Feldman RA, Bastos CO, et al. Evaluation of the protective effect of group $\mathrm{C}$ miningococcal polysaccharide vaccine in children aged 6 to 36 months [Avaliacao do efeito protector de vacina polissacaridica antimeningococica do groupo C, em criancas de 6 A 36 meses]. Rev Inst Adolfo Lutz. 1978;38:77-82. [Portuguese.]

77. Gold R, Artenstein MS. Meningococcal infections: 2. Field trial of group C meningococcal polysaccharide vaccine in 1969-1970. Bull World Health Organ. 1971;45(3):279-282.

78. Rosenstein N, Levine O, Taylor JP, et al. Efficacy of meningococcal vaccine and barriers to vaccination. JAMA. 1998;279(6):435-439.

79. De Wals P, De Serres G, Niyonsenga T. Effectiveness of a mass immunization campaign against serogroup $\mathrm{C}$ meningococcal disease in Quebec. JAMA. 2001;285(2):177-181. 
80. Goldblatt D, Borrow R, Miller E. Natural and vaccine-induced immunity and immunologic memory to Neisseria meningitidis serogroup $\mathrm{C}$ in young adults. J Infect Dis. 2002;185(3):397-400.

81. Vu DM, de Boer AW, Danzig L, et al. Priming for immunologic memory in adults by meningococcal group $\mathrm{C}$ conjugate vaccination. Clin Vaccine Immunol. 2006;13(6):605-610.

82. Southern J, Gelb D, Andrews N, et al. Reactogenicity of meningococcal $\mathrm{C}$ conjugate vaccines when administered at the same time as, or a month prior to or after, tetanus and diphtheria booster vaccinations. Hum Vaccin. 2006;2(6):237-242.

83. Ramsay ME, Andrews N, Kaczmarski EB, Miller E. Efficacy of meningococcal serogroup $\mathrm{C}$ conjugate vaccine in teenagers and toddlers in England. Lancet. 2001;357(9251):195-196.

84. Trotter CL, Andrews NJ, Kaczmarski EB, Miller E, Ramsay ME. Effectiveness of meningococcal serogroup C conjugate vaccine 4 years after introduction. Lancet. 2004;364(9431):365-367.

85. Martínez AI, Domínguez A, Oviedo M, et al. Epidemiology of the meningococcal disease in Catalonia before and after vaccination against serogroup C. Rev Esp Salud Publica. 2009;83(5): 725-735. Spanish.

86. Salleras L, Domínguez A, Cardeñosa N. Dramatic decline of serogroup $\mathrm{C}$ meningococcal disease in Catalonia (Spain) after a mass vaccination campaign with meningococcal $\mathrm{C}$ conjugated vaccine. Vaccine. 2003;21(7-8):729-733.

87. Larrauri A, Cano R, Garcia M, Mateo S. Impact and effectiveness of meningococcal $\mathrm{C}$ conjugate vaccine following its introduction in Spain. Vaccine. 2005;23(32):4097-4100.

88. De Greeff SC, de Melker HE, Spanjaard L, Schouls LM, van Derende A. Protection from routine vaccination at the age of 14 months with meningococcal serogroup $\mathrm{C}$ conjugate vaccine in the Netherlands. Pediatr Infect Dis J. 2006;25(1):79-80.

89. Ibarz-Pavon A, Urwin R, Maiden MC. Effect of the conjugate serogroup $\mathrm{C}$-polysaccharide vaccine on the carriage and population structure of Neisseria meningitidis. In: Eighth Meeting of the European Monitoring Group on Meningococci. Dublin, Ireland; 2005.

90. Ramsay ME, Andrews NJ, Trotter CL, Kaczmarski EB, Miller E. Herd immunity from meningococcal serogroup $\mathrm{C}$ conjugate vaccination in England: database analysis. BMJ. 2003;326(7385): 365-366.

91. Maiden MC, Spratt BG. Meningococcal conjugate vaccines: new opportunities and new challenges. Lancet. 1999;354(9179): 615-616.

92. Lancellotti M, Guiyoule A, Ruckly C, Hong E, Alonso JM, Taha MK. Conserved virulence of $\mathrm{C}$ to $\mathrm{B}$ capsule switched Neisseria meningitidis clinical isolates belonging to ET-37/ST-11 clonal complex. Microbes Infect. 2006;8(1):191-196.

93. Balmer $\mathrm{P}$, Borrow $\mathrm{R}$, Miller $\mathrm{E}$. Impact of meningococcal $\mathrm{C}$ conjugate vaccine in the UK. J Med Microbiol. 2002;51(9):717-722.

94. Ravenscoft N, Feavers IM. Conjugate vaccines. In: Frosch M, Maiden MCJ, editors. Handbook of Meningococcal Disease. Weinheim: Wiley-VCH; 2006:343-370.

95. Prymula R, Peeters P, Chrobok V, et al. Pneumococcal capsular polysaccharides conjugated to protein $\mathrm{D}$ for prevention of acute otitis media caused by both Streptococcus pneumoniae and non-typable Haemophilus influenzae: a randomised double-blind efficacy study. Lancet. 2006;367(9512):740-748.

96. Bilukha OO, Rosenstein N; National Center for Infectious Diseases, Centers for Disease Control and Prevention (CDC). Prevention and control of meningococcal disease: recommendations of the Advisory Committee on Immunization Practices (ACIP). MMWR Recomm Rep. 2005;54(RR-7):1-21.

97. Keyserling H, Papa T, Koranyi K, et al. Safety, immunogenicity, and immune memory of a novel meningococcal (groups A, C, Y, and $\mathrm{W}-135)$ polysaccharide diphtheria toxoid conjugate vaccine (MCV4) in healthy adolescents. Arch Pediatr Adolesc Med. 2005;159(10): 907-913.
98. US Food and Drug Administration (FDA). Vaccines and Related Biological Products Advisory Committee Rockville Maryland, 2004 License Application for the tetravalent meningococcal conjugate vaccine, Menactra, manufactured by Aventis Pasteur, Inc.

99. US Food and Drug Administration (FDA). Menactra, meningococcal (groups A, C, Y, and W135) polysaccharide diphtheria toxoid conjugate vaccine. FDA Statistical Review and Evaluation. Document for the Vaccines and Related Biological Products Advisory Committee (VRBPAC). Rockville (MD): FDA; 2004.

100. Letson GW, Little JR, Ottman J, Miller GL. Meningococcal vaccine in pregnancy: an assessment of infant risk. Pediatr Infect Dis J. 1998;17(3):261-263.

101. McCormick JB, Gusmão HH, Nakamura S, et al. Antibody response to serogroup $\mathrm{A}$ and $\mathrm{C}$ meningococcal polysaccharide vaccines in infants born of mothers vaccinated during pregnancy. J Clin Invest. 1980;65(5):1141-1144.

102. De Andrade Carvalho A, Giampaglia CM, Kimura H, et al. Maternal and infant antibody response to meningococcal vaccination in pregnancy. Lancet. 1977;2(8042):809-811.

103. Robbins JB, Towne DW, Gotschlich EC, Schneerson R. "Love's labours lost": failure to implement mass vaccination against group A meningococcal meningitis in sub-Saharan Africa. Lancet. 1997;350(9081):880-882.

104. Nakhla I, Frenck RW Jr, Teleb NA, et al. The changing epidemiology of meningococcal meningitis after introduction of bivalent $\mathrm{A} / \mathrm{C}$ polysaccharide vaccine into school-based vaccination programs in Egypt. Vaccine. 2005;23(25):3288-3293.

105. Zangwill KM, Schuchat AS, Riedo FX, et al. School-based clusters of meningococcal disease in the United States: descriptive epidemiology and a case-control analysis. JAMA. 1997;277(5): 389-395.

106. Centers for Disease Control and Prevention (CDC). Control and prevention of serogroup $\mathrm{C}$ meningococcal disease: evaluation and management of suspected outbreaks; recommendations of the Advisory Committee on Immunization Practices (ACIP). MMWR Recomm Rep. 1997;46(RR-5):13-21.

107. Centers for Disease Control and Prevention (CDC). Updated recommendations for use of meningococcal conjugate vaccines: Advisory Committee on Immunization Practices (ACIP), 2010. MMWR Morb Mortal Wkly Rep. 2011;60(3):72-76.

108. Centers for Disease Control and Prevention (CDC). Prevention and control of meningococcal disease. MMWR Morb Mortal Wkly Rep. 2005;54(RR-7):1-17.

109. Centers for Disease Control and Prevention (CDC). Updated recommendation from the Advisory Committee on Immunization Practices (ACIP) for revaccination of persons at prolonged increased risk for meningococcal disease. MMWR Morb Mortal Wkly Rep. 2009;58(37):1042-1043.

110. World Health Organization. Managing meningitis epidemics in Africa: a quick reference guide for health authorities and health-care workers. WHO/HSE/GAR/ERI/2010.4. Geneva: WHO; 2010.

111. Thompson MJ, Ninis N, Perera R, et al. Clinical recognition of meningococcal disease in children and adolescents. Lancet. 2006;367(9508):397-403.

112. Tibby SM, Murdoch IA, Durward A. Mortality in meningococcal disease: please report the figures accurately. Arch Dis Child. 2002;87(6):559.

113. Bigham JM, Hutcheon ME, Patrick DM, Pollard AJ. Death from invasive meningococcal disease following close contact with a case of primary meningococcal conjunctivitis: Langley, British Columbia, 1999. Can Commun Dis Rep. 2001;27(2):13-18. English, French.

114. Peltola H. Meningococcal disease: still with us. Rev Infect Dis. 1983;5(1):71-91.

115. Steven N, Wood M. The Clinical Spectrum Of Meningococcal Disease. In: Cartwright K, editor. Meningococcal Disease. Chichester: John Wiley \& Sons; 1995:177-205. 
116. Van Deuren M, Brandtzaeg P, van der Meer JW. Update on meningococcal disease with emphasis on pathogenesis and clinical management. Clin Microbiol Rev. 2000;13(1):144-166.

117. Kim KS. Acute bacterial meningitis in infants and children. Lancet Infect Dis. 2010;10(1):32-42.

118. Kanegaye JT, Soliemanzadeh P, Bradley JS. Lumbar puncture in pediatric bacterial meningitis: defining the time interval for recovery of cerebrospinal fluid pathogens after parenteral antibiotic pretreatment. Pediatrics. 2001;108(5):1169-1174.

119. Guimont C, Hullick C, Durrheim D, Ryan N, Ferguson J, Massey P. Invasive meningococcal disease: improving management through structured review of cases in the Hunter New England area, Australia. J Public Health (Oxf). 2010;32(1):38-43.

120. Lala HM, Mills GD, Barratt K, Bonning J, Manikkam NE, Martin D. Meningococcal disease deaths and the frequency of antibiotic administration delays. $J$ Infect. 2007;54(6):551-557.

121. Ninis N, Phillips C, Bailey L, et al. The role of healthcare delivery in the outcome of meningococcal disease in children: case-control study of fatal and non-fatal cases. BMJ. 2005;330(7506): 1475 .

122. El-Wiher N, Cornell TT, Kissoon N, Shanley TP. Management and treatment guidelines for sepsis in pediatric patients. Open Inflammation J. 2011;4(Supp1 1-M11):101-109.

123. Pollard AJ, Britto J, Nadel S, DeMunter C, Habibi P, Levin M Emergency management of meningococcal disease. Arch Dis Child. 1999;80(3):290-296.

124. Rivers E, Nguyen B, Havstad S, et al. Early goal-directed therapy in the treatment of severe sepsis and septic shock. $N$ Engl J Med. 2001;345(19):1368-1377.

125. Sookhai S, Wang JH, Winter D, Power C, Kirwan W, Redmond HP. Dopamine attenuates the chemoattractant effect of interleukin-8: a novel role in the systemic inflammatory response syndrome. Shock. 2000;14(3):295-299.

126. Schilling T, Gründling M, Strang CM, Möritz KU, Siegmund W, Hachenberg T. Effects of dopexamine, dobutamine or dopamine on prolactin and thyreotropin serum concentrations in high-risk surgical patients. Intensive Care Med. 2004;30(6):1127-1133.
127. Scottish Intercollegiate Guidelines Network. Management of Invasive Meningococcal Disease in Children and Young People: A National Clinical Guideline. Edinburgh: SIGN; 2008.

128. Ellis-Pegler R, Galler L, Roberts S, Thomas M, Woodhouse A. Three days of intravenous benzyl penicillin treatment of meningococcal disease in adults. Clin Infect Dis. 2003;37(5):658-662.

129. McIntyre PB, Berkey CS, King SM, et al. Dexamethasone as adjunctive therapy in bacterial meningitis: a meta-analysis of randomized clinical trials since 1988. JAMA. 1997;278(11):925-931.

130. Van de Beek D, de Gans J, McIntyre P, Prasad K. Corticosteroids for acute bacterial meningitis. Cochrane Database Syst Rev. 2007; 1:CD004405.

131. Canavese F, Krajbich JI, LaFleur BJ. Orthopaedic sequelae of childhood meningococcemia: management considerations and outcome. J Bone Joint Surg Am. 2010;92(12):2196-2203.

132. Borg J, Christie D, Coen PG, Booy R, Viner RM. Outcomes of meningococcal disease in adolescence: prospective, matched-cohort study. Pediatrics. 2009;123(3):502-509.

133. Erickson L, De Wals P. Complications and sequelae of meningococcal disease in Quebec, Canada, 1990-1994. Clin Infect Dis. 1998;26(5):1159-1164

134. Levy C, Taha MK, Weil Olivier C, et al. Association of meningococcal phenotypes and genotypes with clinical characteristics and mortality of meningitis in children. Pediatr Infect Dis J. 2010;29(7) 618-623.

135. Gottfredsson M, Reynisson IK, Ingvarsson RF, et al. Comparative long-term adverse effects elicited by invasive group B and C meningococcal infections. Clin Infect Dis. 2011;53(9):e117-e124.

136. Boeckx WD, Nanhekhan L, Vos GD, Leroy P, Van den Kerckhove E. Minimizing limb amputations in meningococcal sepsis by early microsurgical arteriolysis. J Pediatr Surg. 2009;44(8): 1625-1630.

137. Davies MS, Nadel S, Habibi P, Levin M, Hunt DM. The orthopaedic management of peripheral ischaemia in meningococcal septicaemia in children. J Bone Joint Surg Br. 2000;82(3):383-386.
Risk Management and Healthcare Policy

\section{Publish your work in this journal}

Risk Management and Healthcare Policy is an international, peerreviewed, open access journal focusing on all aspects of public health, policy, and preventative measures to promote good health and improve morbidity and mortality in the population. The journal welcomes submitted papers covering original research, basic science, clinical \& epidemio-

\section{Dovepress}

logical studies, reviews and evaluations, guidelines, expert opinion and commentary, case reports and extended reports. The manuscript management system is completely online and includes a very quick and fair peerreview system, which is all easy to use. Visit http://www.dovepress.com/ testimonials.php to read real quotes from published authors. 